\title{
Promoting vasectomy services in Rwanda
}

\author{
Brian Perry \\ Catherine Packer \\ Dawn S. Chin-Quee \\ Trinity Zan \\ Dominick Shattuck
}

Follow this and additional works at: https://knowledgecommons.popcouncil.org/departments_sbsr-rh How does access to this work benefit you? Let us know!

\section{Recommended Citation}

Perry, Brian, Catherine Packer, Dawn S. Chin-Quee, Trinity Zan, and Dominick Shattuck. 2016. "Promoting vasectomy services in Rwanda." Durham, NC: FHI 360 and Washington, DC: The Population Council, The Evidence Project. 


\section{PROMOTING VASECTOMY SERVICES IN RWANDA}

The Family Planning 2020 (FP2020) movement began in 2012, when more than 150 political leaders at the London Summit on Family Planning committed to provide 120 million women in the world's poorest countries with access to contraceptives by 2020 . FP2020 aims to support the reproductive rights of women and girls and empower them to achieve their reproductive goals. This is done, in part, by ensuring FP clients across the globe are provided with the informed choice of a wide range of high quality contraceptive methods. During this meeting, the Government of Rwanda committed to introducing long acting and permanent contraceptive methods in every hospital and health center. ${ }^{1}$ In addition, the Government of Rwanda has set an ambitious goal of reaching a contraceptive prevalence rate (CPR) of $90 \%$ by $2017^{2}$ and reducing the total fertility rate to 4.5 children by 2020. ${ }^{3}$ Rwanda has made great progress toward these goals and the current trend in FP use is encouraging. Expanding the method mix - by increasing capacity, encouraging demand for vasectomy, and creating male-friendly FP services - can increase modern CPR ${ }^{4}$ and continue Rwanda's momentum.

However, the current range of accessible FP methods, behavior change messaging and interpersonal communication reinforce the notion that FP services are specifically for women. Pervasive misconceptions about vasectomy constrain financial, policy and community support for the method. As a result, men are insufficiently engaged in reproductive health services and women carry the primary responsibility for using contraception.

The truth is vasectomy services provide couples seeking to limit family size with a highly effective, permanent, and malefocused FP alternative without side effects.

\section{Greater integration of vasectomy}

promotion and services is a first step

in expanding the reproductive health paradigm to include men not just as default partners of female clients, but as equal beneficiaries of reproductive health programs.
No-scalpel vasectomy:

- Is PAINLESS, FAST, and EXTREMELY EFFECTIVE

- Requires LITTLE RECOVERY TIME,

- Has ECONOMIC AND HEALTH BENEFITS for the family,

- Has NO SIDE EFFECTS, and

- DOES NOT INTERFERE WITH SEXUAL FUNCTION OR PLEASURE.

Greater education and support for vasectomy at a national level would address the gender imbalance in contraceptive availability and use. Unlike a new female-focused method, meaningful integration of vasectomy into a method mix expands the reproductive health paradigm to include men as users of FP services and promotes couples' fertility as a shared responsibility. This more holistic approach to reproductive health supports an informed choice of a wide range of high quality contraceptive methods.

Vasectomy is the most cost-effective and safest permanent method for meeting the needs of men and women who desire to limit future births (i.e. want no more children). Since 2010, Rwanda has implemented a successful vasectomy program which has increased the uptake of vasectomy nation wide. By continuing to promote and support the voluntary use of vasectomy as part of the overall method mix, Rwanda can help meet its national and international FP commitments and contribute to the development of a more gender equitable society, where men play a supportive and proactive role in their families' health.

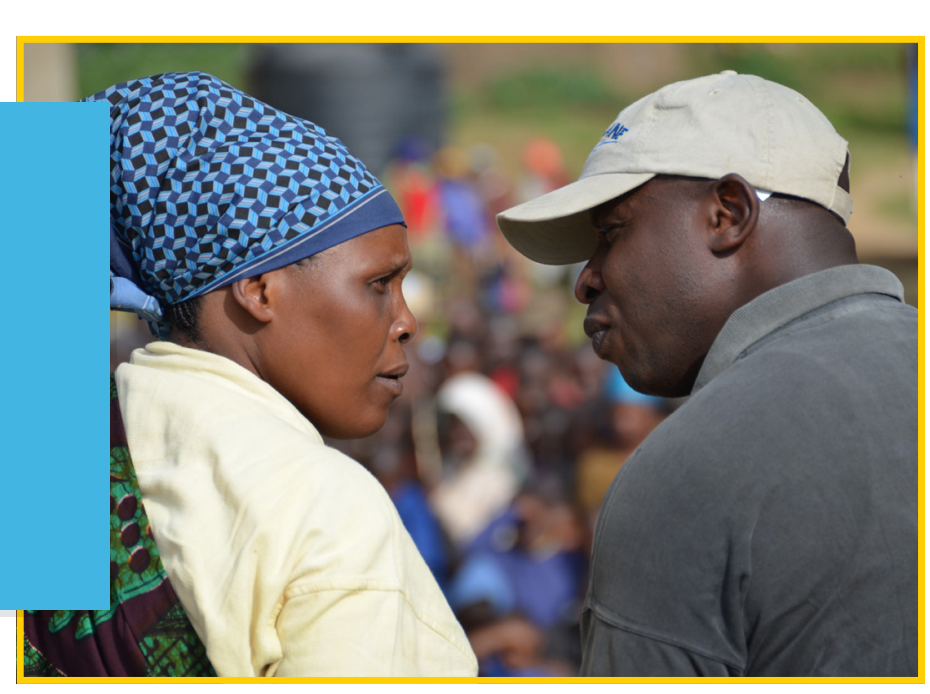




\section{VASECTOMY HELPS INDIVIDUALS AND COUPLES ACHIEVE THEIR DESIRED FAMILY SIZE}

If Rwanda were to achieve its goal of increasing the CPR to 90\% among married women (15-49) by 2017, there would be an estimated 1.3 million total contraceptive users in 2020 in this demographic (assuming the CPR remained at 90\%). If a small percentage of married couples in Rwanda used vasectomy, it would have a direct and lasting impact on public health and reduce the overall costs of FP commodities and services.

Estimated Market Size for Permanent Methods in Rwanda, 20205,6

\begin{tabular}{|lr|cr|r}
\hline Total Female Population & $\mathbf{7 , 1 7 9 , 2 3 1}$ & $\mathbf{7 , 1 4 8 , 1 4 9}$ & Total Male Population \\
Married (15 - 49 years old) & $\mathbf{1 , 2 9 6 , 8 8 7}$ & $\mathbf{1 , 6 9 3 , 7 3 0}$ & Married (15 - 54 years old) \\
\hline Desire to Limit Future Births* & $\mathbf{7 7 4 , 4 1 8}$ & $\mathbf{1 , 1 5 2 , 8 6 9}$ & Desire to Limit Future Births*
\end{tabular}

${ }^{*}$ Excludes men and women who report prior sterilization or infecundity

\section{VASECTOMY EXPANDS THE CHOICE FOR EFFECTIVE PERMANENT METHODS OF CONTRACEPTION}

Over $88 \%$ of married women who reported a desire to limit future births in Rwanda were using either short-term contraceptive methods or no method at all. ${ }^{5}$ Injectables, which have a high rate of discontinuation due to side effects, represent nearly $45 \%$ of the contraceptives used by this population. Vasectomy offers a lifetime of contraceptive protection without fear of side effects.
Contraceptive Use among Married Women (15-49) who want to Limit Future Births in Rwanda ${ }^{5}$
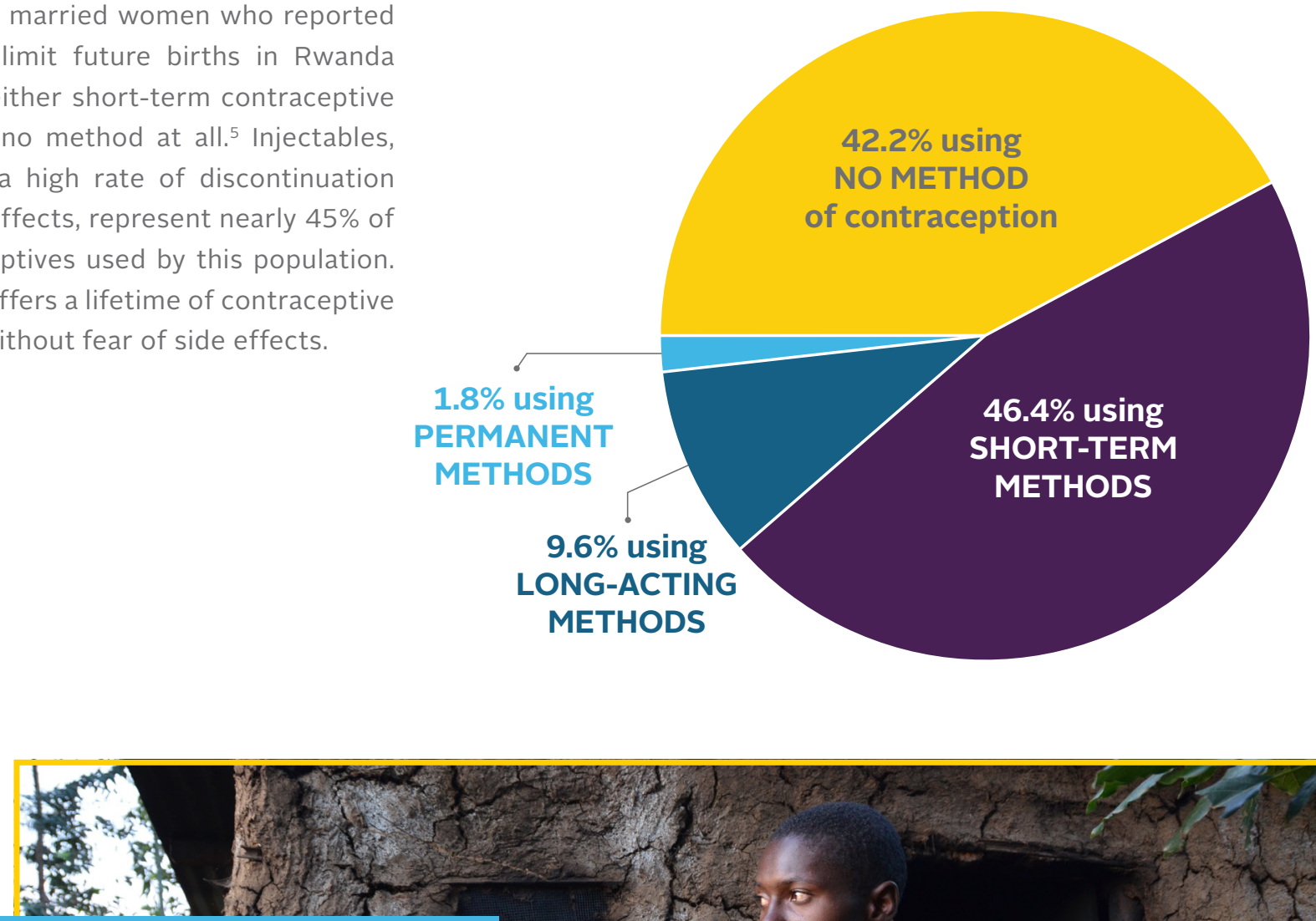

Unmet Need for Limiting:

Couples who want to limit

future births and are currently

using short-term or no method

of contraception are an

important potential market

for vasectomy services.
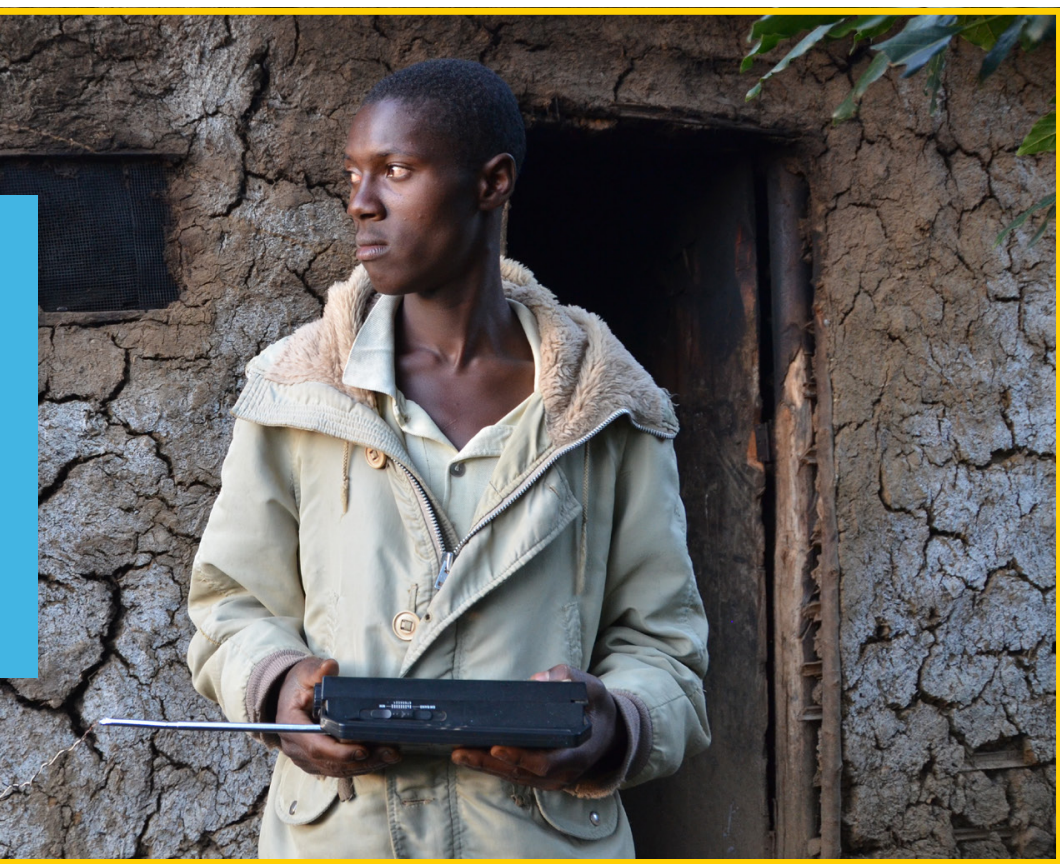
If Rwanda were to achieve its goal of increasing the CPR to $90 \%$ among married women (15-49) by 2017 , there would be an estimated 1.3 million total contraceptive users in 2020 in this demographic (assuming the CPR remained at $90 \%$ ). If a small percentage of married couples in Rwanda used vasectomy, it would have a direct and lasting impact on public health and reduce the overall costs of FP commodities and services.

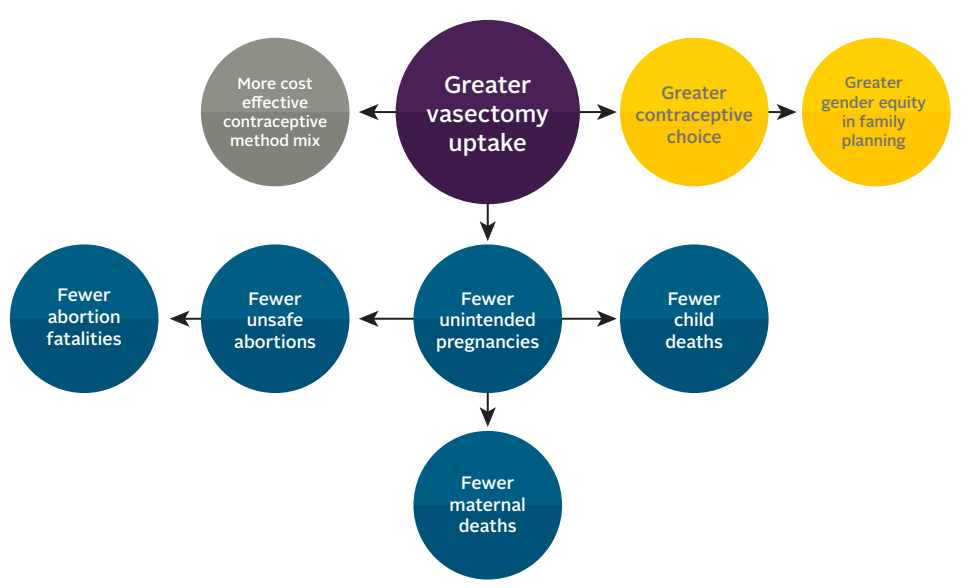

\section{VASECTOMY IS AMONG THE MOST COST-EFFECTIVE FAMILY PLANNING METHODS}

Vasectomy is less expensive per CYPa than all other forms of contraceptives presently provided, with the exception of copper IUDs.7, 8 In Rwanda, increased investment in vasectomy would result in greater savings per CYP in commodity and service costs of the nation's contraceptive method mix.

\section{Cost of Contraceptive Provision per CYP in Rwanda, 20157,8}

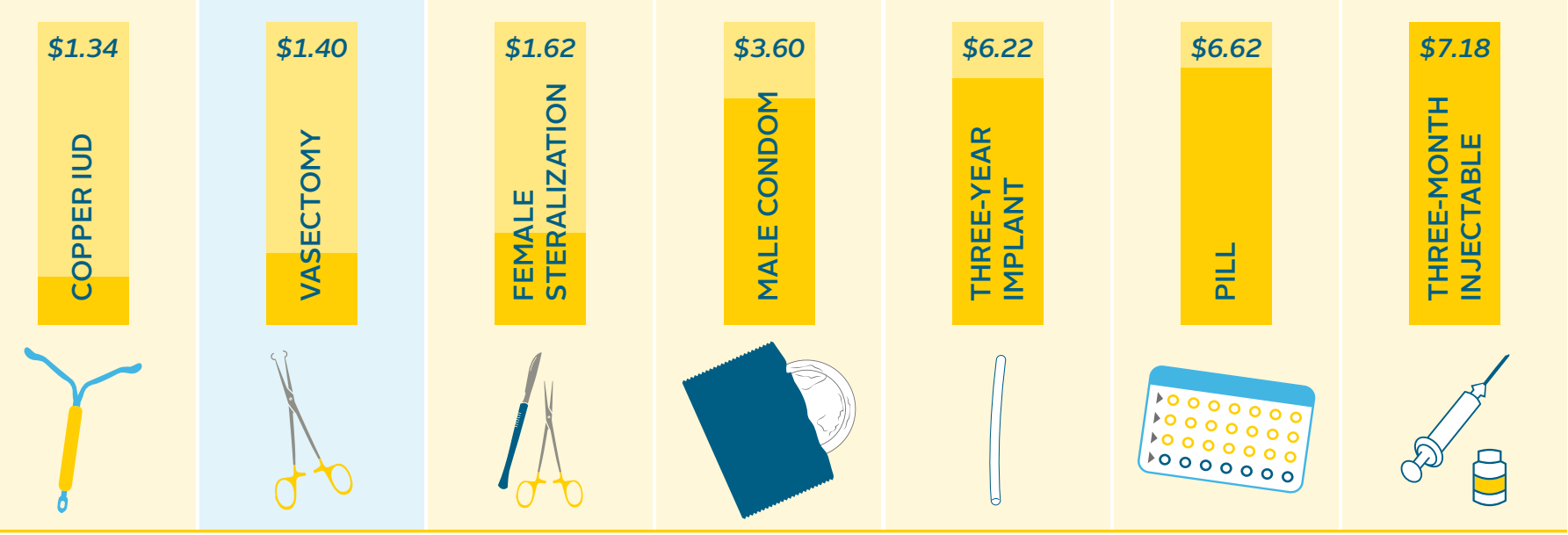

Costs per CYP only reflect direct labor and costs of commodities and consumable supplies and does not take into account other potential costs associated with introducing vasectomy into the market, including demand creation, additional provider trainings or expansion of service coverage.

\section{VASECTOMY CAN CONTRIBUTE TO A LESS EXPENSIVE AND MORE EFFECTIVE METHOD MIX}

For example, if by 2020 , only $5 \%$ of married women (30 to 49) who desire to limit births were to switch from using short-term methods to relying on their partner's vasectomy to achieve their fertility goals, it would improve the cost effectiveness of the method mix for this demographic by over $12 \%$.

This marginal increase in the use of vasectomy for limiting births - equal to 35,069 vasectomies performed over the next 5 years - would improve the public health impact of the method mix by $14 \%$.

${ }^{b}$ Original projections calculated by FHI 360 in 2016.

\section{CUMULATIVE COST-EFFECTIVENESS AND PUBLIC HEALTH IMPACTS (2016-2020) ${ }^{b}$}

\begin{tabular}{|c|c|c|}
\hline & $\begin{array}{l}\text { Current } \\
\text { Method Mix* }\end{array}$ & $\begin{array}{c}\text { Method Mix* } \\
\text { including } 5 \% \\
\text { vasectomy CPR }\end{array}$ \\
\hline Cost per CYP & $\$ 6.21$ & $\$ 5.46$ \\
\hline Total CYP & $1,823,306$ & $2,078,269$ \\
\hline $\begin{array}{r}\text { Unintended pregnancies } \\
\text { averted }\end{array}$ & 525,112 & 598,541 \\
\hline Maternal deaths averted & 2,500 & 2,849 \\
\hline Infant deaths averted & 26,256 & 29,927 \\
\hline Unsafe abortions averted & 156,273 & 178,126 \\
\hline $\begin{array}{r}\text { Abortion case-fatalities } \\
\text { averted }\end{array}$ & 813 & 926 \\
\hline
\end{tabular}

* Among married women (30-49) who want to limit births 


\section{PROGRAM RECOMMENDATIONS}

The recommendations below, adapted from a recent document review ${ }^{9,10}$, may aid policymakers and program implementers in Rwanda to increase demand for and supply of vasectomy services and to create a greater enabling environment for a male-inclusive FP agenda.

\section{CREATE AN ENABLING ENVIRONMENT:}

- Establish supportive policies and political support for male-inclusion and develop a Costed Implementation Plan for FP which includes continued expansion of vasectomy services and demand creation activities.

- To close the gap between FP commitments and available financial support, donors and the government should invest in the most cost-effective method mix to address the changing needs of men, women, and couples over their reproductive lives.

- Address gender-related norms that may negatively impact FP decision-making, by empowering women and couples to talk openly about their reproductive intentions and consider vasectomy as a desirable way to ensure the family's health and well-being.

- Include vasectomy in sexual and reproductive health education for youth, particularly for young men, to begin early sensitization on vasectomy as a viable form of limiting births in the future.

- Create "male-friendly" reproductive health services. For example, train male community health workers to counsel men about their FP options.

\section{INCREASE SUPPLY OF VASECTOMY SERVICES:}

- Focus on initial public-sector capacity building in locations with available teaching medical facilities, existing private-sector vasectomy services and ample demand to sustain skill development.

- Address negative provider biases and attitudes about providing vasectomy services through education and provider testimonials, and ensure providers receive adequate compensation for services.

- Build capacity of current mobile vasectomy services, hospitals and health centers to offer no-scalpel vasectomy with use of fascial interposition and thermal cautery as part of their existing services.
- Continue to invest in sustainable vasectomy skill development by training certified public-sector vasectomy providers as vasectomy trainers.

\section{ENCOURAGE DEMAND FOR VASECTOMY:}

- Engage and support vasectomy "champions" among religious, political, and community leaders, health providers, community health workers and satisfied vasectomy clients.

- Disseminate accurate information about vasectomy; particularly in regard to method safety and its effect on virility and physical strength.

- Explore the motivation and decision-making process of existing groups of men who received a vasectomy to shape future vasectomy messages.

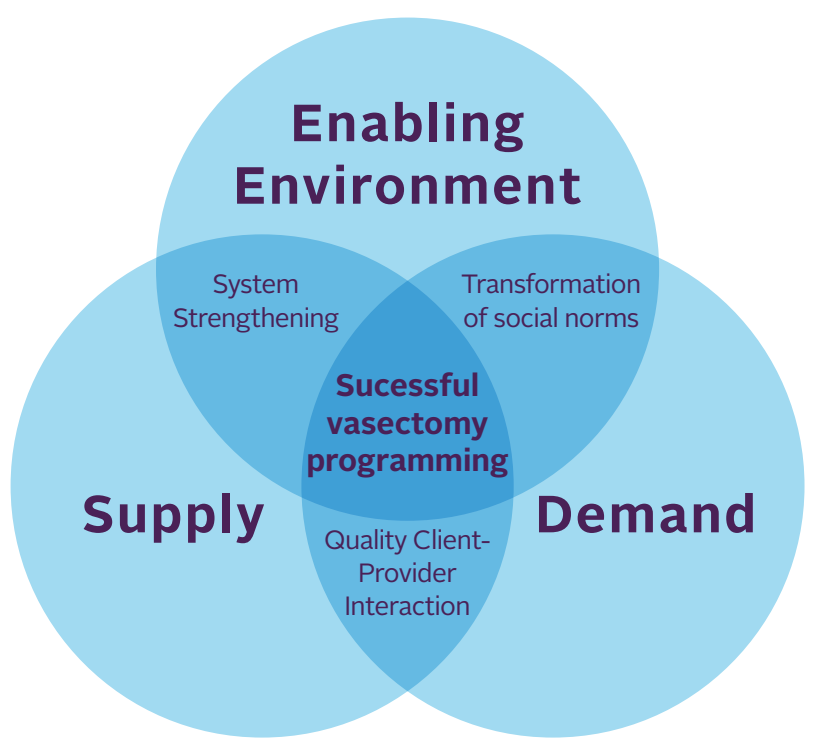

Adapted from EngenderHealth's Supply-Enabling Environment-Demand (SEED) Programming Model ${ }^{\mathrm{TM}}$

Rwanda FP2020 Commitments, Progress \& Transparency. 2012. Available at: http://www.familyplanning2020.0rg/entities/81.

Republic of Rwanda Ministry of Health. Family Planning Strategic Plan, 2012-2016. 2012. Available at: http://www.moh.qov.rw/fileadmin/templates/Docs/Rwanda-Family-PlanningStrategic-2012-2013.pdf.

Maternal and Child Health Integrated Program and the Respond Project. Assessment of Rwanda's National Family Planning Policy and its Five-Year Strategies (2005-2010). 2011. Available at: http://www.respond-project.org/archive/files/4/4.3/4.3.2/Report-2011-Rwanda-Assessment.pdf.

4 Ross J and Stover J. Use of modern contraception increases when more methods become available: analysis of evidence from 1982-2009. Glob Health Sci Pract. 2013;1(2):203-212. National Institute of Statistics of Rwanda, Rwanda Ministry of Finance and Economic Planning, Rwanda Ministry of Health and ICF International. 2012. Rwanda Demographic and Health Survey 2010. RWIR61FL.SAV and RWMR61FL.SAV. Kigali, Rwanda and Calverton, Maryland: National Institute of Statistics of Rwanda National Institute of Statistics of Rwanda and ICF International [Producers]. ICF International [Distributor], 2012.

US Census Bureau. International Database. Last updated July 2015. Available at http://www.census.gov/population/international/data/idb/informationGateway.php.

Tumlinson K, Steiner MJ, Rademacher KH, Olawo A, Solomon M, and Bratt J. 2011. The promise of affordable implants: is cost recovery possible in Kenya. Contraception, 83:88-93.

s Rademacher KH, Solomon M, Pascual C, Njunguru J, Brett T, and Steiner MJ. 2016. Expanding access to a new, more affordable levonorgestrel intrauterine system in Kenya: Perspectives from Key Opinion Leaders. Global Health: Science and Practice. In press.

Perry B, Packer C, Chin Quee D, Zan T, Dulli L, and Shattuck D. Recent experience and lessons learned in vasectomy programming in low-resource settings: a document review. Durham, NC: FHI 360 and Washington, DC: Population Council, the Evidence Project. 2016.

10 Packer C, Perry B, Chin-Quee D, Zan T, and Shattuck D. How to create successful vasectomy programs. Durham, NC: FHI 360 and Washington, DC: The Population Council, the Evidence Project. 2016 


\section{THE EVIDENCE PROJECT}

\section{POPULATION COUNCIL}

4301 Connecticut Avenue, NW, Suite 280

Washington, DC 20008 USA

Tel +1202 2379400

Evidenceproject.popcouncil.org

This work is made possible by the generous support of the American people through the

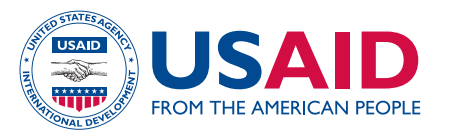

United States Agency for International Development (USAID) under the terms of The

Evidence Project, co-operative agreement no. AID-OAA-A-13-00087. The findings and conclusions are the sole responsibility of the authors and do not necessarily reflect the views of USAID or the United States Government.

The Evidence Project seeks to expand access to high quality family planning/ reproductive health services worldwide through implementation science, including the strategic generation, translation, and use of new and existing evidence. The project is led by the Population Council in partnership with the INDEPTH Network, the International Planned Parenthood Federation, PATH, and the Population Reference Bureau.

FHI 360 is a nonprofit human development organization dedicated to improving lives in lasting ways by advancing integrated, locally driven solutions. Our staff includes experts in health, education, nutrition, environment, economic development, civil society, gender, youth, research and technology - creating a unique mix of capabilities to address today's interrelated development challenges. FHI 360 serves more than 60 countries, all 50 U.S. states and all U.S. territories.

For more information about vasectomy programmatic recommendations, contact:

FHI 360

Mailing address:

359 Blackwell Street,

Suite 200, Durham, NC 27701

Telephone: +19195447040

Fax: +19195447261

Published in March 2016

Suggested Citation:

Perry B, Packer C, Chin-Quee D, Zan T, and Shattuck D. Promoting Vasectomy Services in Rwanda.

Durham, NC: FHI 360 and Washington, DC: The Population Council, the Evidence Project. 2016.

Copyright (c) 2016 FHI 360. All rights reserved. 


\section{PHOTO CITATIONS}

\section{Photo 1 - ID: 8091-27}

During a drama show for hundreds of people in Rwanda, two actors playing a married couple have a stand-off over issues related to reproductive health.

\section{(c) 2012 Kim Burns Case/JHUCCP,}

Courtesy of Photoshare

\section{Photo 2 - ID: 8091-28}

A young man shows his home in Rwanda where he listens to his radio. He says that he has learned a lot about HIV and AIDS from listening to a serial drama on the local radio station, which is supported by the USAID-funded Behavior Change and Social Marketing project.

(c) 2012 Kim Burns Case/JHUCCP, Courtesy of Photoshare 